\title{
DISTRIBUTION OF FIBERS IN SFRC SEGMENTS FOR TUNNEL LININGS
}

\author{
SERGIO CARMONA ${ }^{1}$ \\ Departamento de Obras Civiles, Universidad Técnica Federico Santa María \\ Valparaíso, Chile \\ CLIMENT MOLINS \\ ANTONIO AGUADO \\ Departamento de Ingeniería de la Construcción, \\ Universitat Politècnica de Catalunya, \\ Barcelona, España \\ and
}

FELIPE MORA

MINMETAL

\begin{abstract}
This paper presents research results regarding the distribution of steel fibers in concrete used to build precast tunnel segments for Line 9 of the Barcelona Metro. The fiber distribution was studied using the actual fiber contents obtained by means of crushed cores drilled from different points of three full-scale tunnel lining segments. A statistical analysis determined that the fiber content in the ends of segments tend to be greater than in the central zone. In addition, cores with a diameter of $150 \mathrm{~mm}$ were found to have a lower scatter in the fiber content than smaller diameter specimens. Finally, based on probabilistic approaches, a minimum of 11 cores is proposed to control the fiber content in FRC segments.
\end{abstract}

KEYWORDS: fiber distribution, fiber content, fiber reinforced concrete, tunnel linings.

${ }^{1}$ Corresponding author: sergio.carmona@ usm.cl, Casilla 110- V Valparaíso, Chile. Tel. +56322654382 Fax +56322654115 


\section{INTRODUCTION}

Fiber-reinforced concretes (FRCs) are increasingly applied in structural engineering because fibers enable the reduction or replacement of reinforcement bars. In general, FRCs are used mainly for pavements and shotcrete that are applied to slopes and tunnel supports. However, currently, FRCs are particularly used in the precast industry (Ferreira and Branco 2007; Walraven 2009; De la Fuente et al., 2012a) and in tunnel building projects (Gettu et al., 2004; Kasper et al., 2008; Chiaia et al., 2007, 2009; Caratelli et al., 2001; De la Fuente et al., 2012b), as reflected in various papers presented in international workshops and conferences in recent years (RILEM 2004, 2008, 2012).

Replacing traditional reinforced concrete by FRC has many advantages regarding both structural performance and costs. These advantages are highlighted in the use of precast elements in industrialized processes (Ferrara and Meda, 2006).

The absorption of energy during cracking is one of the most important properties of FRC; however, the reinforcement efficiency provided by fibers depends on (1) the fiber properties: strength, stiffness, and bonding; (2) the fiber distribution: relative fraction, contents, and orientation (Zollo, 1997). Currently, fibers are made of different materials, shapes, and sizes. Choosing the correct fibers depends on the property to be improved. Regarding the influence of the spatial distribution in the concrete mass, many research studies indicate how the variability in FRC properties depends on: (1) the fiber orientation with respect to the stress lines and (2) the variability of the fiber spatial distribution.

To determine the actual reinforcement available in each direction of the concrete volume, due to the relevance of the distribution and orientation of the fibers in the development of suitable and reliable material properties for structural design, many researchers have studied the distribution of fibers theoretically and/or at the laboratory level, for example, Akkaya et al. (2000), Chermant et al. (2001), Chung (2001), Lawler et al. (2003), Dupont and Vandewalle (2005), Ozyurt (2007), Lataste et al. (2008), Lee and Kim (2010), and the comprehensive RILEM TC 162 (2003), among others. Nevertheless, such studies have generally been conducted with small specimens, and only in a very few occasions was the distribution of fibers in real-size structures 
measured (Ferrara and Meda, 2006; Kooiman 1997, 2000).In the present research, the actual distribution of the fibers in precast segments was determined.

According to the above background, in this paper, the results of an experimental campaign performed to determine the volumetric fiber distribution in precast tunnel lining segments that were solely reinforced with fibers for an experimental section of L9 of the Barcelona metro are presented. Based on the results, an estimation of the number of samples required for assessing the fiber content of a tunnel lining segments is presented.

\section{FIBER DISTRIBUTION IN THE FRC}

Factors related to fiber dispersion in the concrete mass are a crucial point to be addressed to promote the reliable use of steel-fiber reinforced concrete (SFRC) as a structural material (Boulekbache et al., 2010). Therefore, controlling and characterizing the fiber dispersion are important topics for developing structural applications of FRC to maximize their mechanical properties and material performance (Woo et al., 2005; Pujadas et al., 2012).

The fiber spatial distribution in the concrete volume is associated with the casting process, i.e., the manner in which concrete is poured into the mold and the vibrating time (Ozyurt, 2007), which depends on the rheological properties of the concrete and the boundary conditions (wall effects) imposed by the mold. In this sense, using selfcompacting concrete (SCC) can help to ensure a uniform fiber dispersion due to their self-compacting rheological stability; as a result, compaction by vibration is not required (Ferrara et al., 2008).

Different destructive and nondestructive techniques have been used to characterize the dispersion and orientation of fiber in a laboratory setting. The fiber distribution may be evaluated through video recording during casting. However, this information is limited to the mass surface (Lataste et al., 2008). Image analysis has been used to determine the distribution inside the concrete mass (Akkaya et al., 2000; Chermant et al., 2001; Lawler et al., 2003). However, this process can be slow and expensive. Chung (2001) investigated the FRC properties during exposure to DC currents and attributed the variations in resistance to microstructural change, such as fiber slip, changes in alignment and/or fiber spacing, when subjected to static or dynamic loads. The electrical characterization method called alternating current - impedance spectroscopy (AC-IS) 
has proven to be effective in monitoring the fiber dispersion, as well as the fiber orientation, segregation and grouping (Manson et al., 2002; Woo et al., 2003). Measuring the electrical resistivity was also found to be able to help to determine the fiber distribution (Lataste et al., 2008). Such electromagnetic methods can be used either for laboratory specimens or small elements (Torrents et al., 2012) or for real size structures

The fiber distribution in precast elements, in an industrial setting, was studied using drilled cores from the FRC, with the fiber orientation determined using X-ray analysis and the fiber content determined by crushing the cores. Using this technique, Kooiman (2000) studied the fiber orientation and distribution in precast tunnel lining segments reinforced with $60 \mathrm{~kg} / \mathrm{m}^{3}$ of steel fibers and concluded that the fibers were not randomly oriented spatially and that bleeding was observed during vibration of the segment, which causes differences in the concrete quality over the thickness of segment, resulting in variations in the FRC properties.

Grunewald et al. (2003), using X-ray images from the cores of precast tunnel lining segments, observed that specimens that were cut perpendicular to the concrete pouring direction exhibited a preferred orientation and that the fiber content was greater than the content obtained in the cores cut along the concrete pouring direction. In addition, the fibers were observed to be distributed homogeneously along the height of the cores.

Ferrara and Meda (2006) studied the relationship among the workability, mechanical properties and fiber distribution of precast elements for roof structures built with ordinary SFRC and self-compacting steel-fiber reinforced concrete (SCSFRC), with the fiber distribution determined by crushing the drilled cores. Based on their results, the dispersion in the fiber distribution is good for specimens larger than $43 \mathrm{~mm}$. Comparing the fiber content through the element thickness, the scatter in the fiber distribution is higher in the cast surface of the SFRC, but with the addition of a viscosity enhancing admixture, the dispersion of the fiber content is lower. The absolute difference between the bottom and top fiber contents reaches $45 \mathrm{~kg} / \mathrm{m}^{3}$ for ordinary SFRC and $18 \mathrm{~kg} / \mathrm{m}^{3}$ for SCSFRC. They also used X-ray images of the cores to study the fiber distribution through the cross section of cores and found good homogeneity in most of the tested cores. However, the decrease of viscosity due to environmental effects could influence the segregation of fibers. 
A more recent approach is the use of numerical models based on fluid dynamics to predict the fiber orientation, especially in self-compacting concrete, taking in account the type of structural element and the concrete casting method in works (Orbe, 2013).

\section{CONSTRUCTION OF THE TUNNEL LINING SEGMENTS AND THE EXPERIMENTAL DETAILS}

This research is part of a series of studies aimed to optimize the use of a steel-fiber based reinforcement in the precast segments used for the lining of the Line 9 tunnel of the Barcelona subway. These studies were performed by the Department of Construction Engineering at the Universitat Politècnica de Catalunya at the request of Gestió d'Infraestructures S.A., the public company managing the project.

In 2004, an experimental section was built, composed of thirty segments for the tunnel lining, which were reinforced solely with $60 \mathrm{~kg} / \mathrm{m}^{3}$ of steel fibers, that is, the maximum amount that allowed the use of the available resources, to gain experience in this type of work, as concluded in earlier studies (Gettu et al., 2005). The instruments for measuring and loading were placed in one of the rings to perform tests on site (Molins and Arnau, 2013). Similarly, other segments reinforced with fibers were built to obtain more information on their actual behavior (Mora et al., 2009).

The tunnel section under this investigation is lined with five standard segments (A) and 2 skewed segments (B and C) to allocate the key segment (K). Each segment encompasses a sector a $48^{\circ}$, except the key one, which covers $24^{\circ}$, as shown in Figure 1. The ring is a universal type ring, with an average width of $1.80 \mathrm{~m}$.

\subsection{Tunnel lining segments}

The 350-mm thick tunnel lining segments were precast in the factory with concrete of a characteristic compressive strength $\left(f_{c k}\right)$ of $50 \mathrm{MPa}$ at 28 days and a deformation modulus of approximately $38.0 \mathrm{GPa}$ at the same age. Concrete was reinforced with $60 \mathrm{~kg} / \mathrm{m}^{3}$ of hooked-end steel fibers of a $1-\mathrm{mm}$ diameter and $50-\mathrm{mm}$ length, provided in bags and bulk. The steel yielding strength was $1000 \mathrm{MPa}$, which ensured that failure did not occur by fiber tension, but by pulling them out. The steel was specified to have a flexural strength equivalent to a 3-mm deflection $\left(f_{c t, k e q 300}\right)$ of $3.2 \mathrm{MPa}$, as determined according to the Belgian flexural test (NBN 15-238, 1992). The concrete mix proportions are presented in Table 1. 
In the study, each segment has a volume of approximately $3.3 \mathrm{~m}^{3}$, and the casting is performed by taking concrete from the mixer to the mold in a $1.5-\mathrm{m}^{3}$ capacity mobile hopper, as shown in Figure 2. Compaction is performed during casting concrete by four vibrators placed at the bottom of the mold. The compaction energy could be regulated if necessary by decreasing the power of some vibrators or turning them off. This way, a great homogeneity of concrete is achieved, avoiding the segregation of coarse aggregate and/or fibers by excessive vibration.

Once casting is completed, the top surface of the tunnel lining is smoothed manually. Next, the segments are moved to a fog room at a temperature between $40^{\circ}$ to $45^{\circ} \mathrm{C}$ for 5 hours. The segments are demolded after curing, and then, gaskets and packers are placed. Next, the segments are moved to the stockyard, where the cores used for this research were drilled.

\subsection{Results of Quality Control of the SFRC}

The concrete used in the segments was controlled through the compressive strength $\left(f_{c}\right)$ and the flexural strength $\left(f_{c t}\right)$ according to the UNE 83507 (AENOR, 2004a) and UNE 83509 (AENOR, 2004b) standards, respectively. The results obtained from the control test are presented in Table2. As found in the table, the compressive strengths vary from a minimum of $47.6 \mathrm{MPa}$ to a maximum of $60.2 \mathrm{MPa}$; in the flexural tests, the first crack strength varies between 5.5 $\mathrm{MPa}$ and $7.3 \mathrm{MPa}$ and the equivalent tensile strengths $\left(f_{c t, e q 300 k}\right)$ vary between a minimum of $4.8 \mathrm{MPa}$ and a maximum of $7.4 \mathrm{MPa}$, according to standard NBN B 15-238 (1992).

Table 2 also indicates that the compressive strength has a coefficient of variation $(\mathrm{CoV})$ significantly lower than the flexural strengths and that the $\mathrm{CoV}$ of the equivalent tensile strength is higher than the $\mathrm{CoV}$ of the resistance to the first crack.

\subsection{Drilling and testing of the cores}

The fiber content at different locations of the segments was measured from cores drilled from 3 different segments, corresponding to different rings cast at different ages. The fiber distribution along the segments was analyzed by dividing them in three zones: (1) center, (2) corners, and (3) intermediate zone of the segment. Figure 3 shows all of the cores drilled in each segment, using 3 different diameters $(d=150 \mathrm{~mm}, d=100 \mathrm{~mm}$ and 
$d=75 \mathrm{~mm})$ in the central zone and only one diameter $(d=150 \mathrm{~mm})$ in the other two other zones (corners and intermediate).

Figure 4 shows the drilling process, which is straight and perpendicular to the surface of tunnel lining segment. The drill was continuously watered throughout the process to reduce the temperature, thus preventing the cores from being damaged by heat, and to reduce dust.

All of the cores had an average length of $350 \mathrm{~mm}$ and three different diameters (150 $\mathrm{mm}, 100 \mathrm{~mm}$ and $75 \mathrm{~mm}$ ), as aforementioned; each of the cores was cut to obtain cylinders that were slender and that had a height/diameter $(h / d)$ ratio of 1 . This geometry is required to perform the Barcelona $(\mathrm{BCN})$ test, according to the UNE 83515 (AENOR, 2010) standard. In this manner, 2, 3 and 4 specimens were obtained from the cores of $150 \mathrm{~mm}, 100 \mathrm{~mm}$, and 75-mm diameters, respectively. The Wall effect in the volume of the studied concrete was minimized by discarding the core ends. After cutting, the samples were weighed. The height and circumference of each sample were measured, and then the average volume was calculated.

\subsection{Barcelona test}

The Barcelona (BCN) test was developed by Molins et al. $(2006,2009)$ based on the Double Punch Test (DPT) proposed by Chen (1970), with the aim of having a suitable test for the characterization of the properties and the systematic quality control of FRC in works. This test was standardized in Spain by AENOR (2010).

The BCN test has many advantages with respect to the flexural tests, among which, the following are highlighted: (1) the use of relatively small cylindrical specimens of $d=h$ $=150 \mathrm{~mm}$, i.e., $h / d=1$, which can be molded or cut from standardized cylinders of $d=$ $150 \mathrm{~mm} \times h=300 \mathrm{~mm}$ or from cores drilled from existing structures; (2) a conventional compression testing machine is required; and (3) the specimens present a high fracture surface so that the properties of the FRC may be quantified through various fracture planes.

As seen in Figure 5a, in this test, the specimen is subjected to compressive stress by means of two wedges with a diameter of $a=d / 4$. The test is conducted under actuator displacement control at a rate of $0.5 \mathrm{~mm} / \mathrm{min}$. During the test, the applied load and the circumferential deformation measured at half the height of the specimen should be 
constantly recorded to obtain the $P-T C O D$ response of the FRC, as shown in Figure $5 b$.

According to the standard UNE 83515 (AENOR, 2010), the peak load, $P_{f}$, is used to calculate the first peak strength, $f_{c t}$, using equation (1):

$$
f_{c t}=\frac{4 P_{f}}{9 \pi a h}
$$

where $a$ is the diameter of the loading wedge and $h$ is the specimen height. The residual strengths of the FRC, $f_{c t R x}$, defined as the unitary loads corresponding to a given circumferential deformation, Rx, may be calculated using expression (2):

$$
f_{c t R x}=\frac{4 P_{R x}}{9 \pi a h}
$$

where $P_{R x}$ is the load corresponding to circumferential deformation $R_{x}$, as shown in Figure 2.

When the cracks open as a result of the stress state on the concrete, the circumferential deformation corresponds to the Total Crack Opening Displacement (TCOD) and the energy dissipated by the FRC during the cracking process may be calculated as:

$$
E(T C O D)=\int_{0}^{T C O D} P(T C O D) d(T C O D)
$$

where $E(T C O D)$ is the energy dissipated by the FRC at a given value of $T C O D$, as shown in the curve of Figure $5 b$, which is directly proportional to the toughness determined using the bending test specified in the Belgian standard NBN B $15-238$ (Molins et al. 2009).

In this research, all of the drilled cores were tested by means of the $\mathrm{BCN}$ test to determine the indirect tensile strength and the toughness. These tests were performed using a hydraulic testing system IBERTEST MEH $3000 \mathrm{~W}$ with a 3-MN capacity and under stroke displacement control at a rate of $0.25 \mathrm{~mm} / \mathrm{min}$. Two steel punches with a diameter equal to one-fourth of the specimen diameter were used for loading each specimen. The total crack opening displacement (TCOD) was measured using a chain extensometer MTS 632.12F - 20 of 10-mm range, which was placed at the half height of the specimen. For this study, the test was stopped when the TCOD reached an opening 
of $6 \mathrm{~mm}$. The tests results are presented in Table 3, where the cracking load $\left(P_{\max }\right)$, the residual strength, and the energy dissipated by the FRC for TCOD values equal to $2 \mathrm{~mm}$ and $6 \mathrm{~mm}$ are given along with the coefficient of variation and the minimum and maximum values.

\subsection{Measurement of the fiber content}

After the BCN tests, all specimens were crushed using a jaw crusher. The fibers and smaller particles of steel were collected from the remains using a magnet. Next, all of the collected fibers were weighted to calculate the actual fiber content of each specimen. The results obtained from this procedure are presented in Table 4, and the results are analyzed in the next section.

\section{ANALYSIS OF THE RESULTS}

The results are presented both globally, i.e., considering all of the available data, and individually, i.e., for each diameter of the specimens. The analysis of the results include the determination of the fiber distribution in the volume of the segment, the fiber distribution across the segment thickness, the effect of the core's size on the amount of fiber, and the minimum number of samples required to control the fiber content.

Before performing each analysis, all data were subjected to the Dixon test to remove aberrant data. Using the procedure proposed by Verma and Quiroz - Ruiz (2006), it was concluded that there is no need to remove any data for confidence intervals of $95 \%$ and higher.

The criterion of Kolmogorov - Smirnov was used in each case to verify the data normality, which is applicable to small or medium sample sizes (ACHE, 2003). According to this model, the more the data fit to the reference curve, the more normal the distribution, as shown in Figure 6a. This result is analytically confirmed when the parameter $p \geq 0.05$.

\subsection{Global analysis}

This analysis was performed using all of the values of fiber contents presented in Table 4, by using the three core diameters sampled. The global average obtained was 60.4 $\mathrm{kg} / \mathrm{m}^{3}$, with a standard deviation $s=12.1 \mathrm{~kg} / \mathrm{m}^{3}$ and a coefficient of variation of $20.1 \%$. This mean value exactly matches the dose of fibers used for constructing the segments. 
However, this variable ranges between $28.5 \mathrm{~kg} / \mathrm{m}^{3}$, that is, the value obtained from a $100-\mathrm{mm}$ diameter specimen, and $96.1 \mathrm{~kg} / \mathrm{m}^{3}$ that is, the value obtained from a $150-\mathrm{mm}$ diameter core. Lower amounts of fibers were found to be obtained in the central zone of segments and the highest concentration of fibers was found in the corners.

\subsection{Fiber distribution in the segments}

The analysis of the fiber distribution in the segment volume was performed by using data obtained from the cores with $d=150 \mathrm{~mm}$. The fiber content at each sampling point where cores were drilled was evaluated using the average content of both parts of each core, that is, the extrados and the intrados, as presented in Table 5.

These data also fit the normality test with $p=0.132$, as shown in Figure $7 \mathrm{a}$. The absolute frequency histogram shown in Figure $7 \mathrm{~b}$ corresponds to the results grouped into five classes of a $10 \mathrm{~kg} / \mathrm{m}^{3}$ amplitude from $40 \mathrm{~kg} / \mathrm{m}^{3}$. Figure $7 \mathrm{~b}$ also includes the curve with a normal cumulative distribution for the mean value and the standard deviation of the sample.

The average fiber content was $64.7 \mathrm{~kg} / \mathrm{m}^{3}$, with a standard deviation $s=8.52 \mathrm{~kg} / \mathrm{m}^{3}$ and a $\mathrm{CoV}=13.2 \%$. Figure $8 \mathrm{a}$ shows the mean content of each sampling point and the corresponding coefficient of variation. These results indicate that larger amounts of fibers are found at the ends of the segments and the lowest are found in the central zone, which corresponds to the area where concrete was poured into the mold during segments casting, as shown in Figure 2. This trend is consistent with the results presented by Kooiman (2000).

Discarding the results obtained from segment 3, which are significantly lower than those obtained from the other segments, produces an average content of $67.3 \mathrm{~kg} / \mathrm{m}^{3}, \mathrm{~s}=$ $2.91 \mathrm{~kg} / \mathrm{m}^{3}$, and $\mathrm{CoV}$ of $4.3 \%$. As shown in Figure $8 \mathrm{~b}$, the fiber distribution is more homogeneous throughout the segment volume. In this analysis, the higher value of fiber content is obtained in the central zone, where the concrete drops from the hopper and the concrete of the last layer does not flow.

\subsection{Distribution of fibers along the thickness of the segments}

The fiber distribution across the segment thickness was evaluated after analyzing the fiber contents determined in the extrados and intrados parts of the 150-mm diameter cores. The data corresponding to the intrados side fit the normal distribution, with a 
parameter value $p$ of 0.261 , as shown in Figure 9a. Meanwhile, the results from the extrados fit a log-normal distribution (Figure 9b).

The intrados samples exhibit a higher amount of fibers than the extrados samples, while the scatter is slightly lower in the extrados samples, as presented in Table 6 . This trend could be an effect of the vibrating process, as described in section 3.1.

\subsection{Specimen size effect on the fiber content control}

The size effect of the specimen on the fiber content was analyzed by using the results from cores drilled from the central zone of the segments. For each set of data, the fitting to the normal distribution is presented in Figure 10a, while the histograms prepared with $10 \mathrm{~kg} / \mathrm{m}^{3}$ amplitude classes are shown in Figure $10 \mathrm{~b}$.

Statistical analysis of the results of the fiber contents determined for each tested diameter indicate that the highest average amount was obtained from the specimens of $d$ $=150 \mathrm{~mm}$ (Table 7). The variation coefficient of data from the three tested diameters was found to remain virtually constant. The minimum fiber contents obtained from the cores of $d=100 \mathrm{~mm}$ and $d=75 \mathrm{~mm}$ were approximately $50 \%$ of the nominal amount used to build the segments. Regarding the maximum values obtained, there are no significant differences among the different tested volumes, and they were, on average, $33 \%$ higher than the nominal amount used during construction.

\subsection{Minimum number of samples for the control of the fiber content}

To establish a minimum number of samples for controlling the fiber content in the FRC, a lower tolerance limit of the fiber content, $\rho_{L}$, was defined as:

$$
\rho_{L}=\rho_{s}-s_{1} \times t_{1-\alpha, v}
$$

where $\rho_{s}$ is the fiber content specified in the project; $s_{1}$ is the likely standard deviation of the FRC to be controlled, which is a function of the concrete casting conditions, the control in the works, and the sampling planning; and $t_{1-a, v}$ is the value of the $t$-student distribution for a confidence level $\alpha$, with $v=n-1$ degrees of freedom.

By dividing both sides of equation (4) by the specified fiber content, $\rho_{s}$, a relative lower tolerance limit, $\rho_{o}$, for the specified fiber content can be calculated with the following equation: 


$$
\rho_{o}=\frac{\rho_{L}}{\rho_{s}}=1-C V_{1} \times t_{1-\alpha, v}
$$

where $C V_{1}$ is the expected coefficient of variation, $\mathrm{CoV}$, for fiber content in concrete. Using values of the CoV of 5, 10, 15, and 20\%, the diagrams shown in Figure 11 were produced by taking data from between 3 and 21 samples and of the confidence levels of 90 and $95 \%$.

Diagrams of Figure 11 show that if few samples are available, then a tolerance limit must be established that is quite low with respect to the specified fiber content. Furthermore, this limit is significantly lower when both the level of confidence and the expected coefficient of variation are increased.

The diagrams show that for sample sizes smaller than 7 and 11 specimens, for levels of confidence of $90 \%$ and $95 \%$, respectively, the relative lower limit of tolerance is highly sensitive and varies sharply when the number of specimens decreases.

To apply this criterion to the available data, the results of the 21 cores with a150-mm diameter given in Table 5 were used to produce 1000 confidence intervals, $C I_{100(1-\alpha) \%}$, with confidence levels, $\alpha$,of $90 \%$ and $95 \%$ and random samples of size $n$ from 3 to 21 data. The lower limit of each confidence interval was determined by using the mean and standard deviation of each random sample, defined as (Devore, 2012):

$$
C I_{100(1-\alpha) \%}=\left[\bar{X}-t_{1-\alpha, v} \frac{s}{\sqrt{n}} ; \infty[\right.
$$

where $\bar{X}$ is the mean and sis the standard deviation of each random sample.

Taking the minimum value of the lower limits among the 1000 confidence intervals, for each sample size and confidence interval, the diagrams in Figure 12 were obtained for both confidence levels: $90 \%$ and $95 \%$. These minimum values are plotted along with the lower limits of tolerance for the fiber content obtained using equation (6) for $\rho_{s}=60$ $\mathrm{kg} / \mathrm{m}^{3}$ and the coefficients of variation given in Figure 11.

According to the diagrams shown in Figure 12, it is proposed that the minimum number of samples required to control the fiber content should be such that the minimum value of the lower limits of the confidence intervals are above the lower limit of tolerance defined by the following equation: 


$$
\rho_{L}=\left(1-C V_{1} t_{1-\alpha, v}\right) \times \rho_{s}
$$

In this case, it can be established that, to expect a coefficient of variation of the fiber content of less than $10 \%$, it will require at least 11 samples, with both confidence levels of $90 \%$ as $95 \%$; in this manner, none of the minimum values of the confidence intervals will be less than the lower limit of tolerance of the fiber content calculated using equation (7).

\section{CONCLUSIONS}

It can be concluded from the study that the global average fiber content in the analyzed segments is $60.4 \mathrm{~kg} / \mathrm{m}^{3}$, with a standard deviation $s=12.1 \mathrm{~kg} / \mathrm{m}^{3}(\mathrm{CoV}$ of $20.1 \%)$. This measured average content fits the nominal content of $60 \mathrm{~kg} / \mathrm{m}^{3}$ of fibers prescribed in the design of the segments.

Analyzing the fiber content in different sized specimens was found to produce different results. An average fiber content of $64.7 \mathrm{~kg} / \mathrm{m}^{3}$ was obtained using $150-\mathrm{mm}$ diameter cores. Although this value is greater than the dose of fibers used, it can be justified because of the high concentration of fibers in the corners, which reaches $67.4 \mathrm{~kg} / \mathrm{m}^{3}$, while throughout the central zone, the concentration is $61.2 \mathrm{~kg} / \mathrm{m}^{3}$ (including the intermediate zone). At the same time, the concentration of the fiber results obtained with smaller diameter specimens, all of which were cut in the central zone of segments, are slightly lower, averaging $55.8 \mathrm{~kg} / \mathrm{m}^{3}$ for specimens of $d=100 \mathrm{~mm}$ and $60.2 \mathrm{~kg} / \mathrm{m}^{3}$ for specimens of $d=75 \mathrm{~mm}$.

The available results for the 150 -mm diameter cores drilled from different points of the segments indicate a greater fiber content at the corners, tending to be higher in the intrados than in the extrados. This trend is consistent with the results available in the literature.

The results of segments 1 and 2 exhibit a more homogeneous distribution of fibers. In this analysis, higher value of fiber content was reached in the center zone, where the concrete drops from the hopper and the last layer does not flow.

As expected, comparing the fiber contents obtained in specimens with different diameters, the lowest variation coefficient is obtained for the specimens of $d=150 \mathrm{~mm}$. As a result, the use of 150 -mm cores is recommended for determining the fiber content. 
Finally, a criterion to establish a lower limit of tolerance for the fiber content is proposed as a function of the design fiber content, the expected coefficient of variation, and the confidence level. In the case of the studied SFRC, a minimum of 11 samples are required to obtain a $\mathrm{CoV}$ lower than $10 \%$ for both confidence levels used $(90 \%$ and $95 \%)$.

\section{ACKNOWLEDGEMENTS}

The authors thank Gestió d'Infrastructures S.A. (G.I.S.A.) (At present Infraestructures.cat) for providing facilities to develop this research. The stay in Barcelona of Dr. Carmona during this research was financed by Project USM 26.11.43, and the Department of Construction Engineering of the UPC, Barcelona, Spain.

\section{REFERENCES}

AENOR, 2004. UNE 83507 - Hormigones con fibras de acero y/o polipropileno. Rotura por compresión. AEN/CNT 83 - Hormigón, Madrid (in Spanish).

AENOR, 2004. UNE 83509 - Hormigones con fibras de acero. Rotura por flexotracción. AEN/CNT 83 - Hormigón, Madrid (in Spanish).

AENOR, 2010. UNE 83515 - Hormigones con fibras. Determinación de la resistencia a fisuración, tenacidad y resistencia residual a tracción. Método Barcelona. AEN/CTN 83 - Hormigón, Madrid (in Spanish).

ACHE, 2003. Control Estadístico del Hormigón Estructural, Ed. ACHE, Madrid (in Spanish).

Akkaya, Y., Picka, J., Shah, S. P., 2000. Spatial distribution of aligned short fibers in cement composites. ASCE J Mater Civ Eng. 12, 272 - 279.

Boulekbache, B., Hamrat, M., Chemrouk, M., Amziane, S., 2010. Flowability of fibrereinforced concrete and its effect on the mechanical properties of the material. Constr Build Mater. 24, 1664 - 1671.

Caratelli, A., Meda, A., Rinaldi, Z., Romualdi, P., 2011. Structural behavior of precast tunnel segments in fiber reinforced concrete. Tunn Undergr Space Technol. 26, $284-$ 291. 
Chiaia, B., Fantilli, A. P., Vallini, P., 2007. Evaluation of minimum reinforcement ratio in FRC members and application to tunnel linings. Mater Struct. 40, $593-604$.

Chiaia, B., Fantilli, A., Vallini, P., 2009. Combining fiber-reinforced concrete with traditional reinforcement in tunnel linings. Engineering Structures. 31, $1600-1606$.

Chermant, J., Chermant, L., Coster, M., Dequiedt, A., Redon, C., 2001. Some fields of applications of automatic image analysis in Civil Engineering. Cem Concr Compos. 23, $157-169$.

Chung, D., 2001. Applied materials science: applications of engineering materials in structural, electronics, thermal, and other industries.CRC Press, Boca Raton.

De La Fuente, A., Escariz, R. C., De Figueiredo, A.D., Molins, C. Aguado, A., 2012.A new design method for steel fibre reinforced concrete pipes. Constr Build Mater. 30, $547-555$.

De La Fuente, A., Pujadas, P., Blanco, A.,Aguado, A., 2012. Experiences in Barcelona with the use of fibres in segmental linings. Tunn Undergr Space Technol. 27, 60 - 71.

Devore, J., 2012. Probabilidad y estadística para ingeniería y ciencias, 8th ed.Thomson, México (in Spanish).

Dupont, D., Vandewalle, L., 2005. Distribution of steel fibres in rectangular sections. Cem Concr Compos. 27, $391-398$.

Ferrara, L.,Meda, A., 2006. Relationships between fibre distribution, workability and the mechanical properties of SFRC applied to precast roof elements. Mater Struct. 39, $411-420$.

Ferrara, L., Park, Y., Shah, S. P., 2008. Correlations among fresh state behavior, fiber dispersion and toughness properties of SFRCs. ASCE J Mater Civ Eng. 20, 493 - 501.

Ferreira, J. C., Branco, F. A., 2007.Structural application of GRC in telecommunication towers. Constr Build Mater. 21, $19-28$.

Gettu, R., Barragan, B., Garcia, T., Ramos, G., Fernandez, C., Oliver, R., 2004. Steel fiber reinforced concrete for the Barcelona metro line 9 tunnel lining, in: Di Prisco, M., 
Felicetti, R., Plizzari, G.A. (Eds.),Proceedings of the $6^{\text {th }}$ RILEM Symposium on FRC (BEFIB 2004)RILEM PRO 39, Bagneux, pp. 141 - 156.

Gettu, R., Gardner, D. R., Saldivar, H., Barragan, B.E., 2005. Study of the distribution and orientation of fibers in SRFC specimens". Mater Struct. 38, 31 - 37.

Grünewald, S., Walraven, J.C., Obladen, B., Zegwaard,J.W., Langbroek, M.,Nemegeer, D., 2003.Tunnel segments of self-compacting steel fibre reinforced concrete, inWallevik, O., Nielsson, I. (Eds.), Proceedings of the 3rd International RILEM Symposium on Self-Compacting Concrete RILEM PRO 33, Bagneux, pp 715 - 724.

Kasper, T., Edvardsen, C., Wittneben, G., Neumann, D., 2008.Lining design for the district heating tunnel in Copenhagen with steel fibre reinforced concrete segments. Tunn Undergr Space Technol. 23, 574 - 587.

Kooiman, A. G., 1997. Design calculations of SFRC segments for application in the Second Heinenoord tunnel (in Dutch). Delft University of Technology, Netherlands.

Kooiman, A. G., 2000. Modelling steel fibre reinforced concrete for structural design, Delf University of Technology, Netherlands.

Lataste, J. F., Behloul, M., Breysse, D., 2008. Characterization of fibres distribution in a steel fibre reinforced concrete with electrical resistivity measurements. NDT\&E International. 41, $638-347$.

Lawler, J., Wilhelm, T., Zampini, D., Shah, S. P., 2003. Fracture processes of hybrid fiber-reinforced mortar. Mater Struct. 36, 197 - 208.

Manson, T. O., Campo, M.A., Hixson, A. D., Woo, L. Y., 2002. Impedance spectroscopy of fiber reinforced cement composites. Cem Concr Compos. 24, 457 465 .

Molins, C., Aguado, A., Marí, A.R., 2006, Quality Control test for SFRC to be used in precast segments. Tunn Undergr Space Technol. 21, 423 - 424.

Molins, C., Aguado, A., Saludes, S., 2009, Double Punch Test to control the energy dissipation in tension of FRC (Barcelona test). Mater Struct. 42, 415 - 425. 
Molins, C., Arnau, O., 2012. Experimental and analytical study of the structural response of segmental tunnel linings based on an in situ loading test. Part 1: Test configuration and execution. Tunn Undergr Space Technol. 26, 764 - 777.

Mora, F., Aguado, C., Molins, C., 2009.Distribución y orientación de fibras en dovelas aplicando el ensayo Barcelona.Hormigón. 931, 28 - 37 (in Spanish).

NBN 15-238, 1992.Tests on Fibre Reinforced Concrete - Bending Test on Prismatic Samples. Norme Belge, Institut Belge de Normalisation (IBN), Brussels, Belgium.

Orbe, A., 2013. Optimización del uso de hormigones autocompactantes reforzados con fibras de acero en aplicaciones convencionales de resistencias moderadas. Universidad del País Vasco. Bilbao.

Ozyurt, N., Mason, T., Shah, S., 2007. Correlation of fiber dispersion, rheology and mechanical performance of FRCs. CemConcrCompos. 29, 70 - 79.

Pujadas, P. Blanco, A. De La Fuente, A., Aguado A., 2012. Cracking behaviour of FRC slabs with traditional reinforcement. Mater Struct. 45, $707-725$.

RILEM, 2004. Proceedings Pro039: 6th International RILEM Symposium on Fiber Reinforced Concrete (BEFIB 2004). Ed M. Di Prisco, R. Felicetti, G.A. Plizzari, Bagneux, France.

RILEM, 2008. Proceedings Pro060: 7th RILEM International Symposium of Fibre Reinforced Concrete: Design and Applications (BEFIB 2008). Ed R. Gettu, Bagneux, France.

RILEM, 2012. Proceedings Pro088: 8th RILEM International Symposium of Fibre Reinforced Concrete: challenges and opportunities (BEFIB 2012). Ed J. A.O. Barros, Bagneux, France.

RILEM TC 162-TDF, 2003.Round-robin analysis of the RILEM TC 162-TDF Beambending test: Part 3 - Fibre distribution.MaterStruct. 36, $631-635$.

Torrents, J.M., Blanco, A., Pujades, P., Aguado, A., Juan, P., Sánchez, M.A., 2012. Inductive method for assessing the amount and orientation of steel fiber in concrete. Mater Struct. 45, 1577 - 1592. 
Verma, S., Quiroz - Ruiz, A., 2006. Critical values for six Dixon tests for outliers in normal samples up to sizes 100, and applications in science and engineering. Revista Mexicana de Ciencias Geológicas. 23, 133 - 161.

Walraven, J. C., 2009. High performance fiber reinforced concrete: progress in knowledge and design codes. Mater Struct. 42, 1247 - 1260.

Woo, L. Y., Wansom, S., Hixson, A. D., Campo, M.A., Mason, T. O., 2003. A universal equivalent circuit model for the impedance response of composites. ASCE J Mater Civ Eng. 38, $2265-2270$.

Woo, L. Y., Wansom, S., Ozyurt, N., Mu, B., Shah, S. P., Mason, T. O., 2005.Characterizing fiber dispersion in cement composites using AC-impedance spectroscopy. Cem Concr Compos. 27, $627-636$.

Zollo, R. F., 1997. Fiber-reinforced concrete: an overview after 30 years of development. Cem Concr Compos. 19, 107 - 122. 


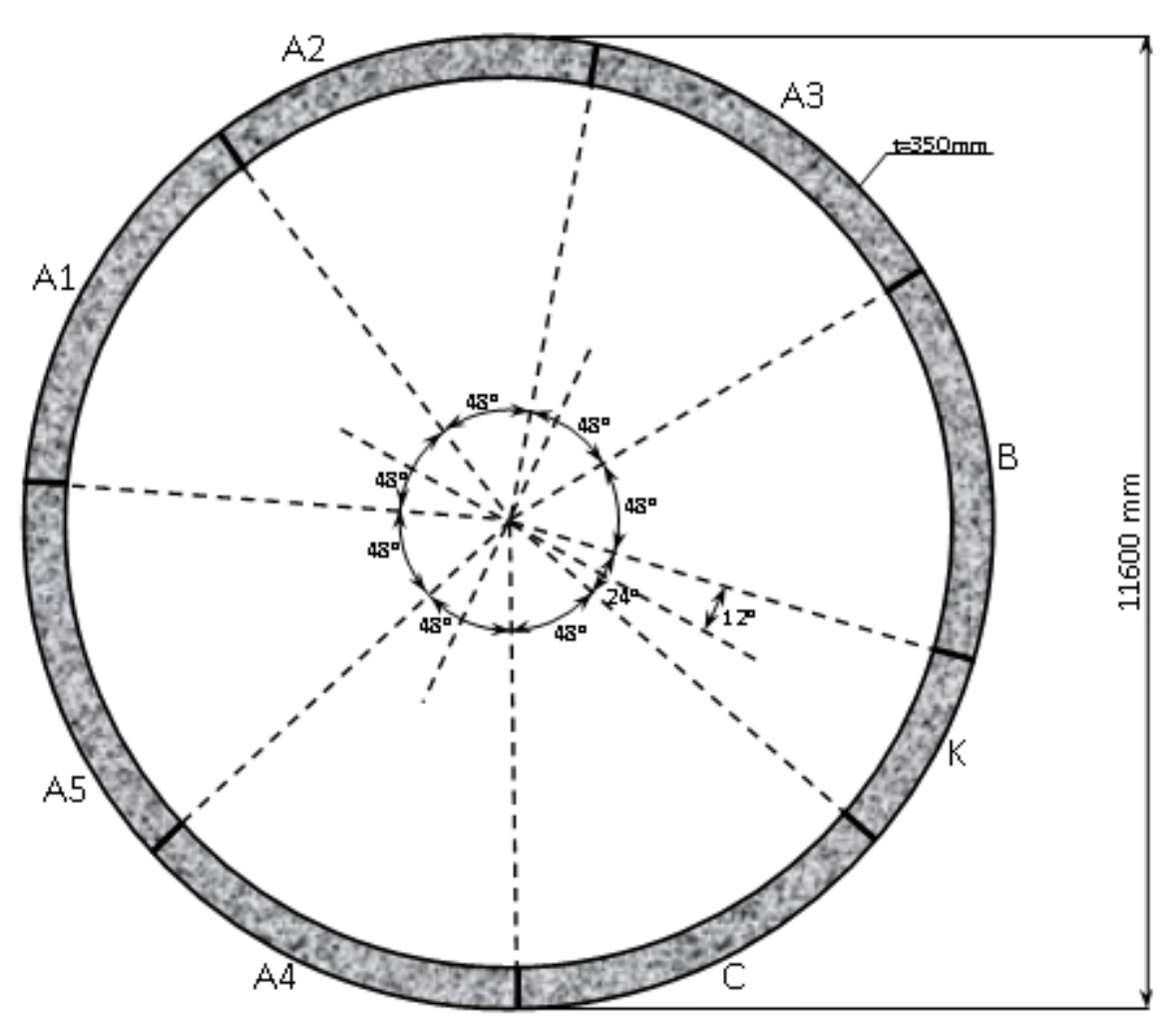

Figure 1: Sketch with the cross section of rings used in construction of the experimental section of Line 9 of the Barcelona underground. 



Figure 2. Construction of the tunnel lining segments. 


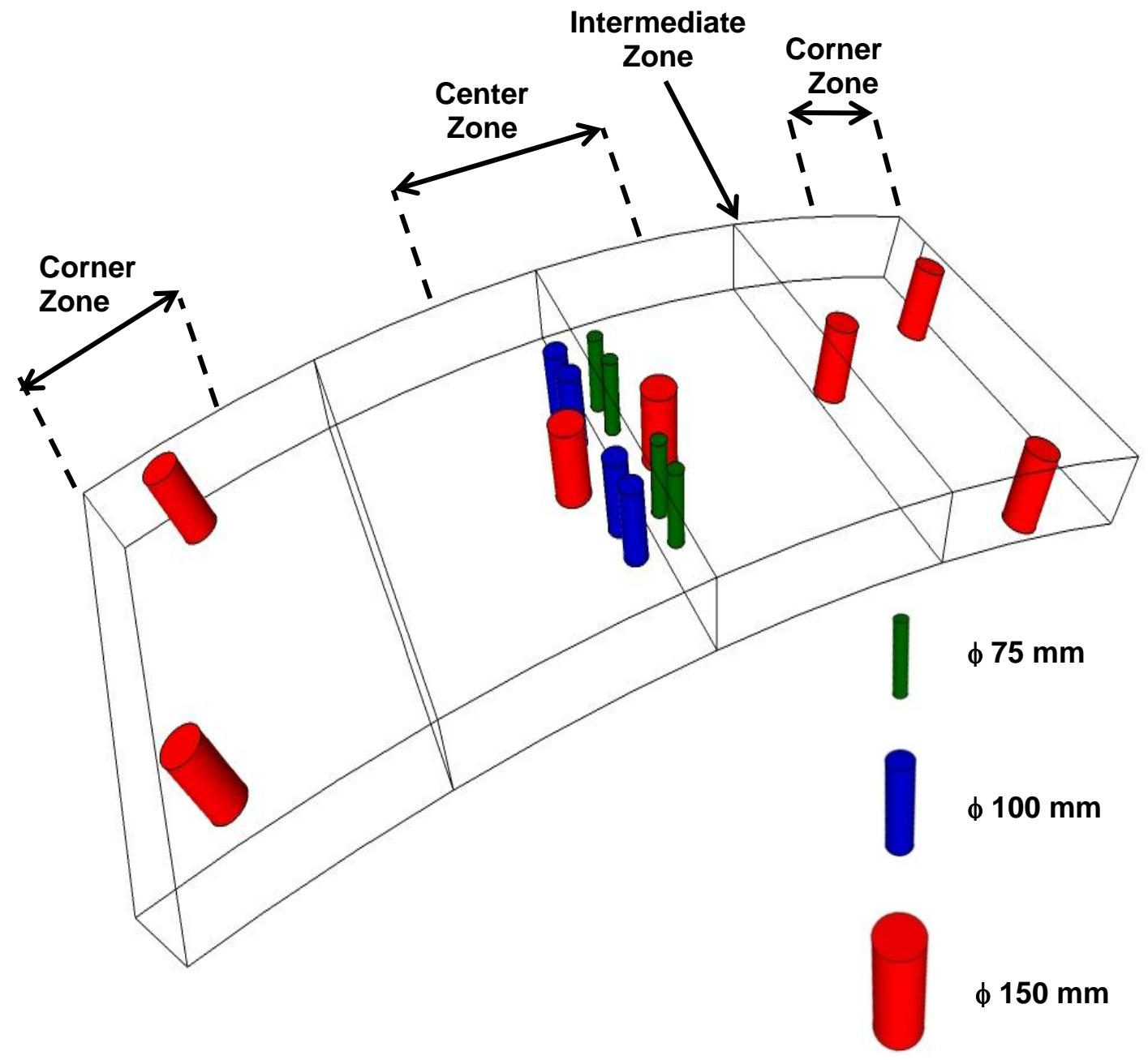

Figure 3. Sampling locations where cores were drilled in each of the three tunnel lining segments.


Figure 4. Drilling cores from tunnel lining segments 




(a)

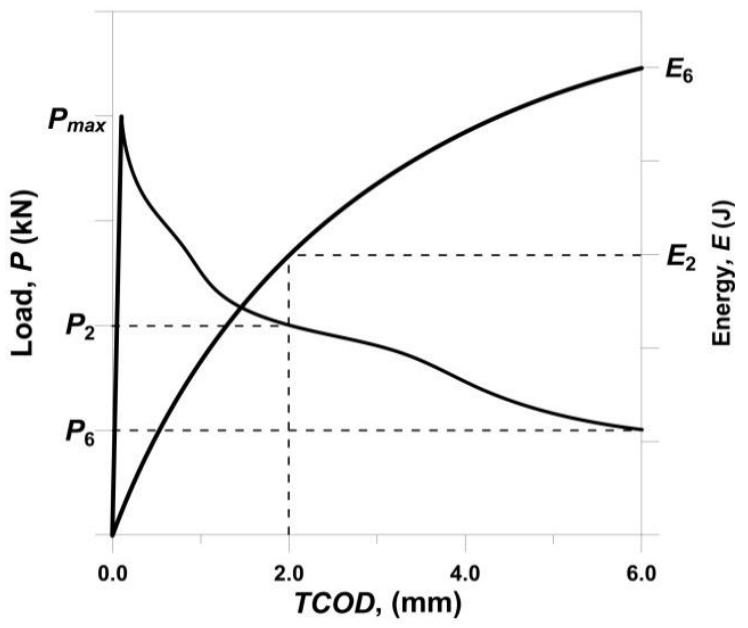

(b)

Figure 5. (a) BCN test setup; (b) Typical Load - TCOD and Energy - TCOD diagrams obtained by the $\mathrm{BCN}$ test.
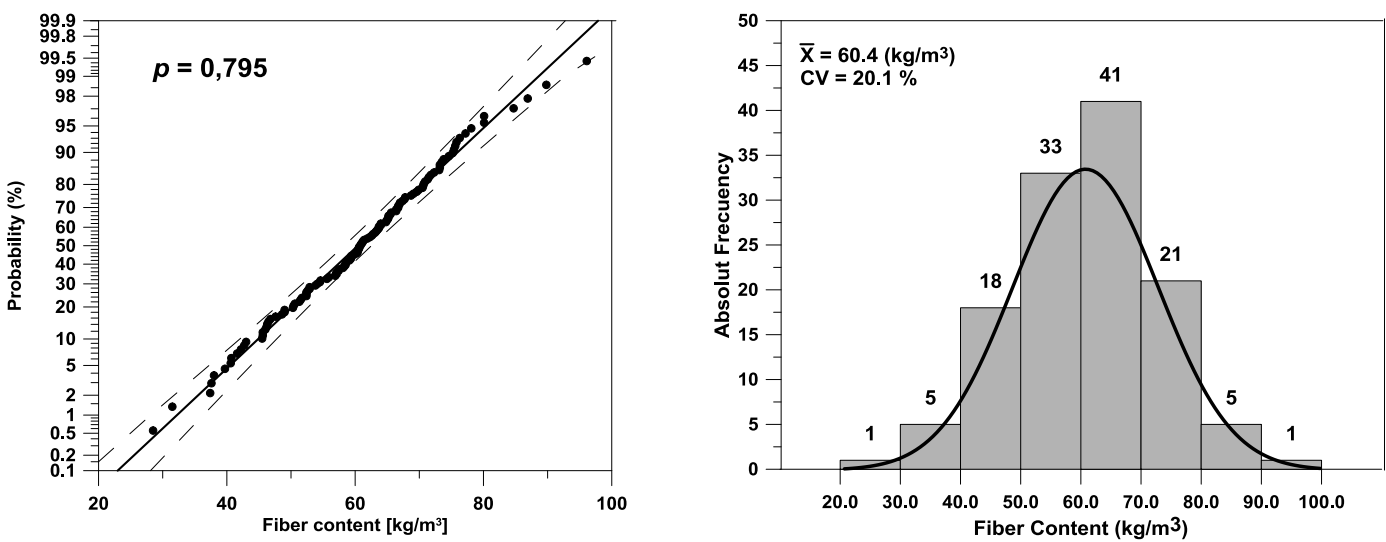

Figure 6. Global analysis results: (a) normality test, (b) histogram. 


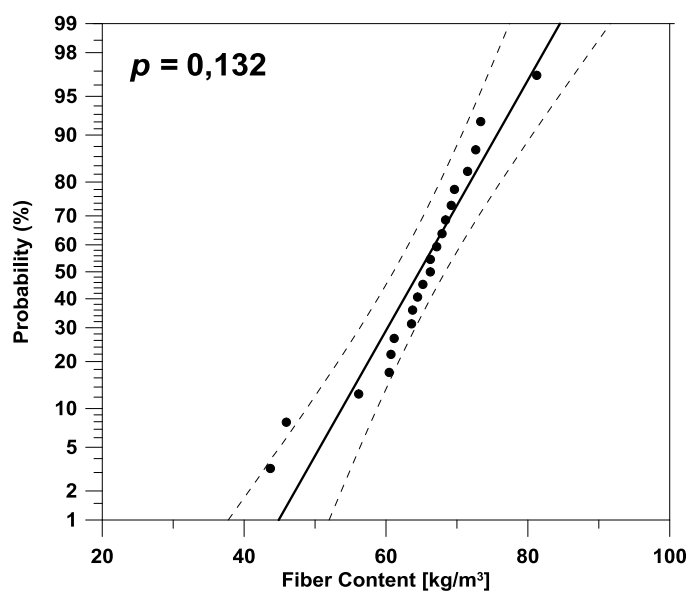

(a)

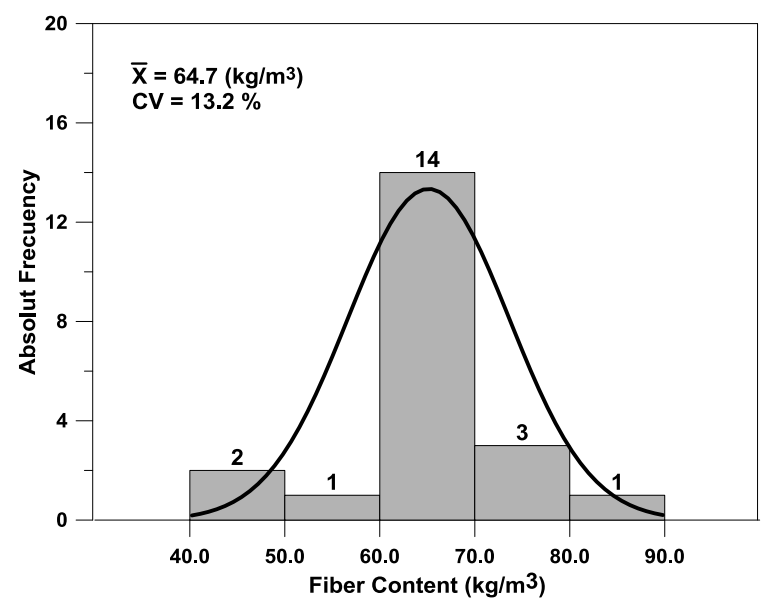

(b)

Figure 7 (a) Checking data normality, (b) Cumulative frequency histogram and cumulative normal distribution. 


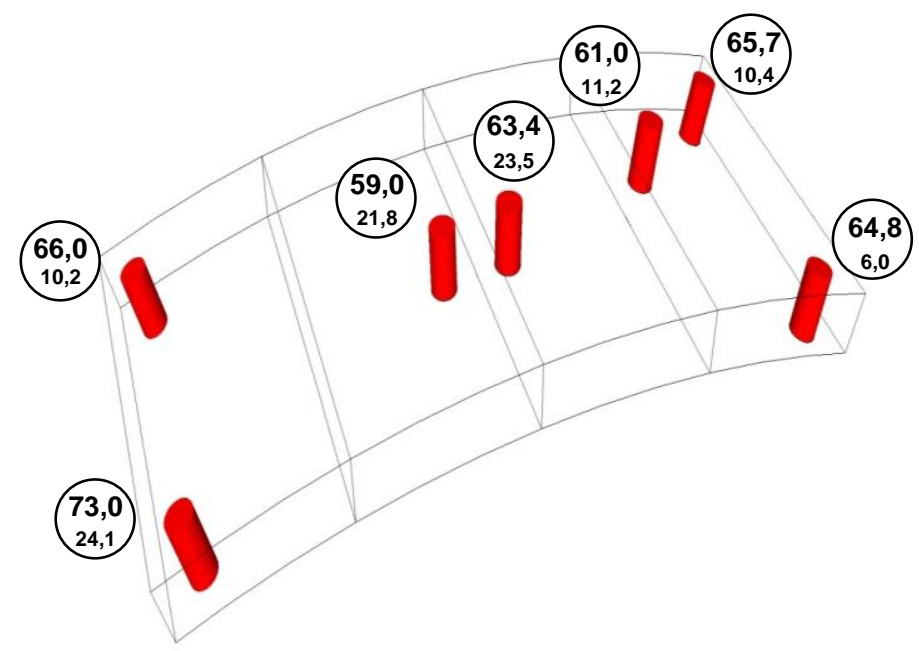

(a)
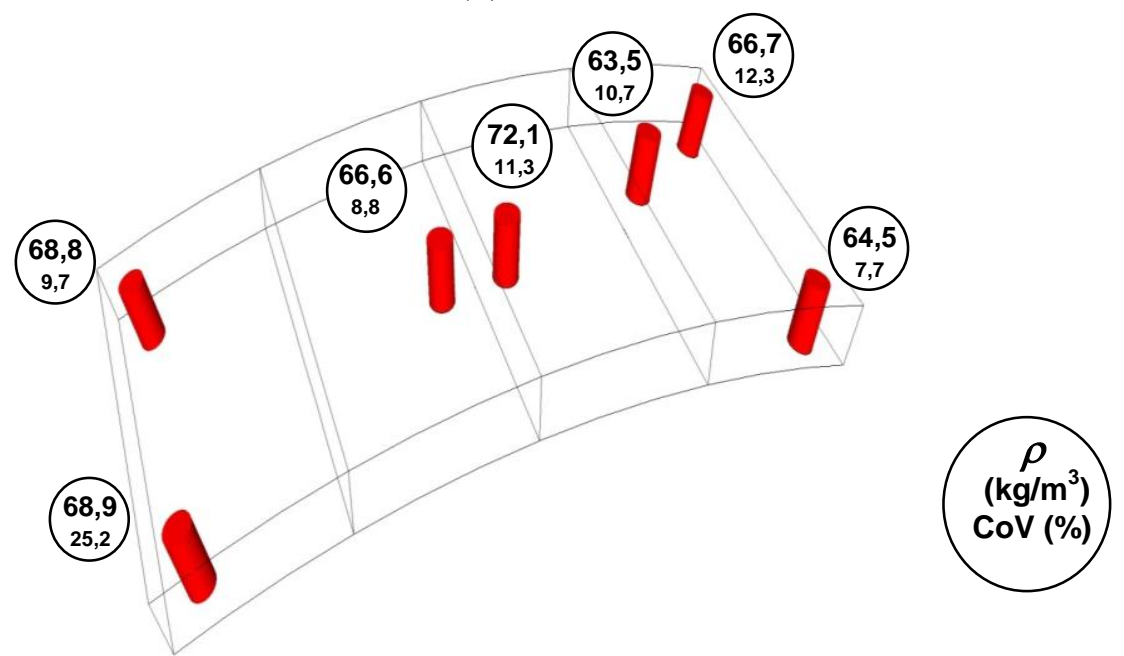

(b)

Figure 8. Fiber content $(\rho)$ at each sampling point: (a) Average of all studied segments and (b) Average of only Segments 1 and 2. 

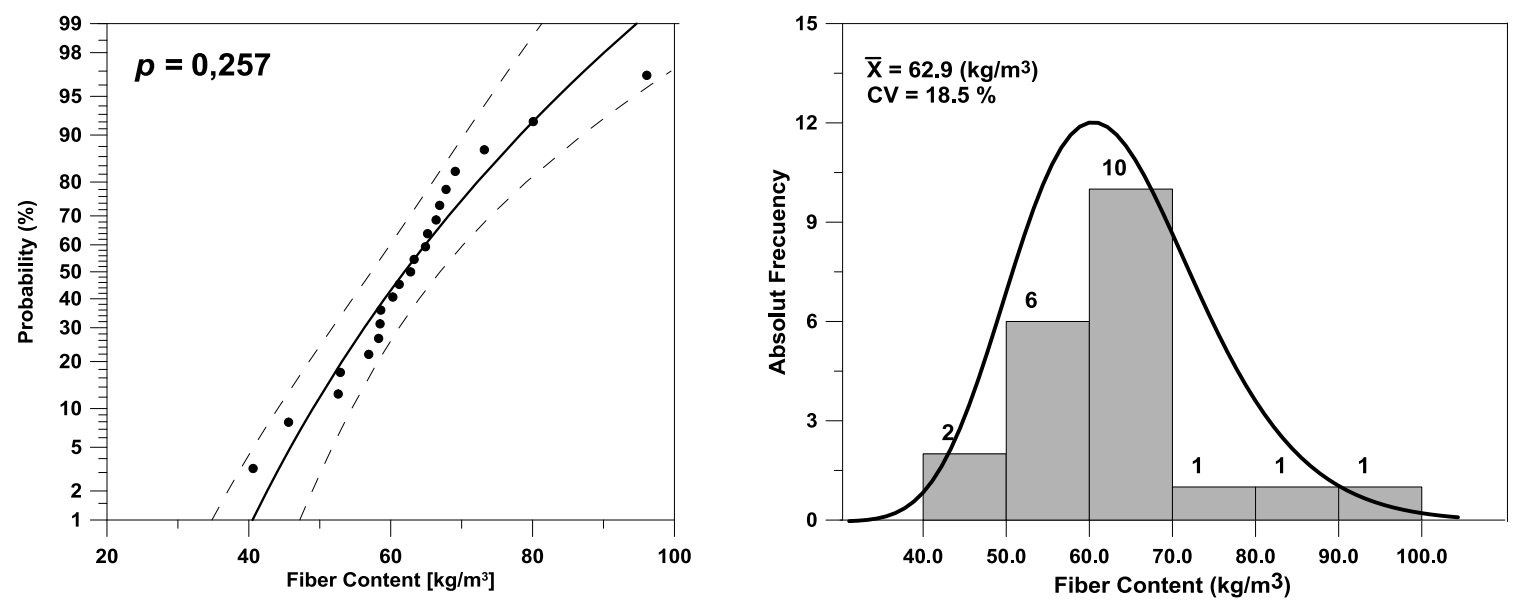

(a)
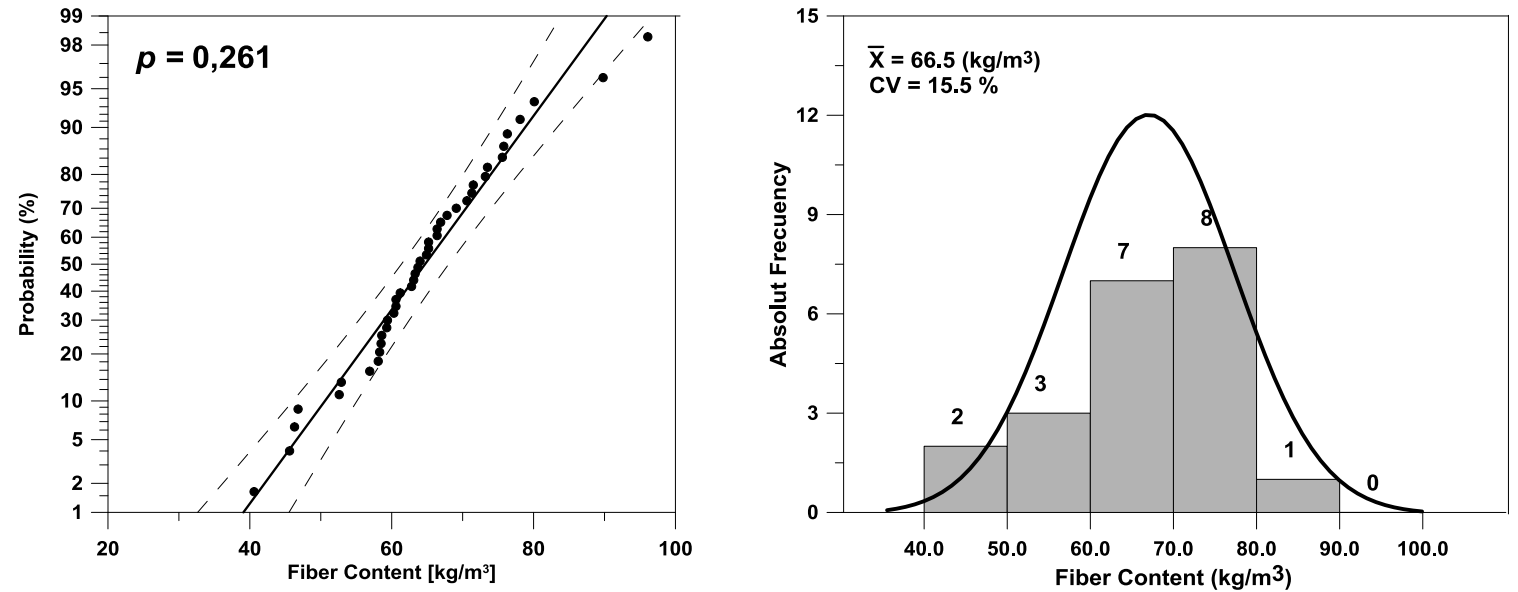

(b)

Figure 9. Amount of fibers through the segments thickness: (a) Extrados side, and (b) Intrados side. 

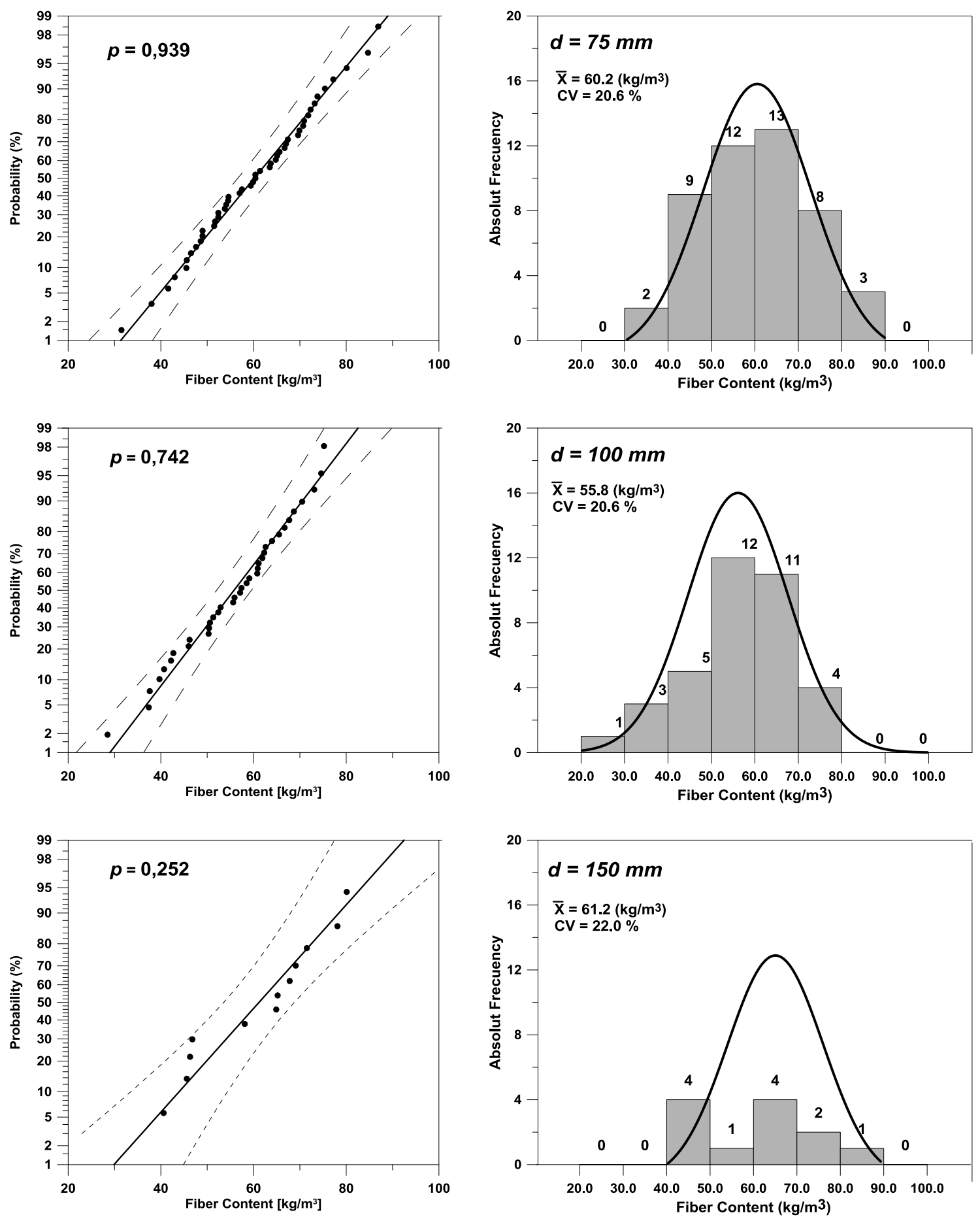

(a)

(b)

Figure 10. Fibers contents of each tested diameter: (a) tests of normality, (b) histograms and normal distribution curve. 

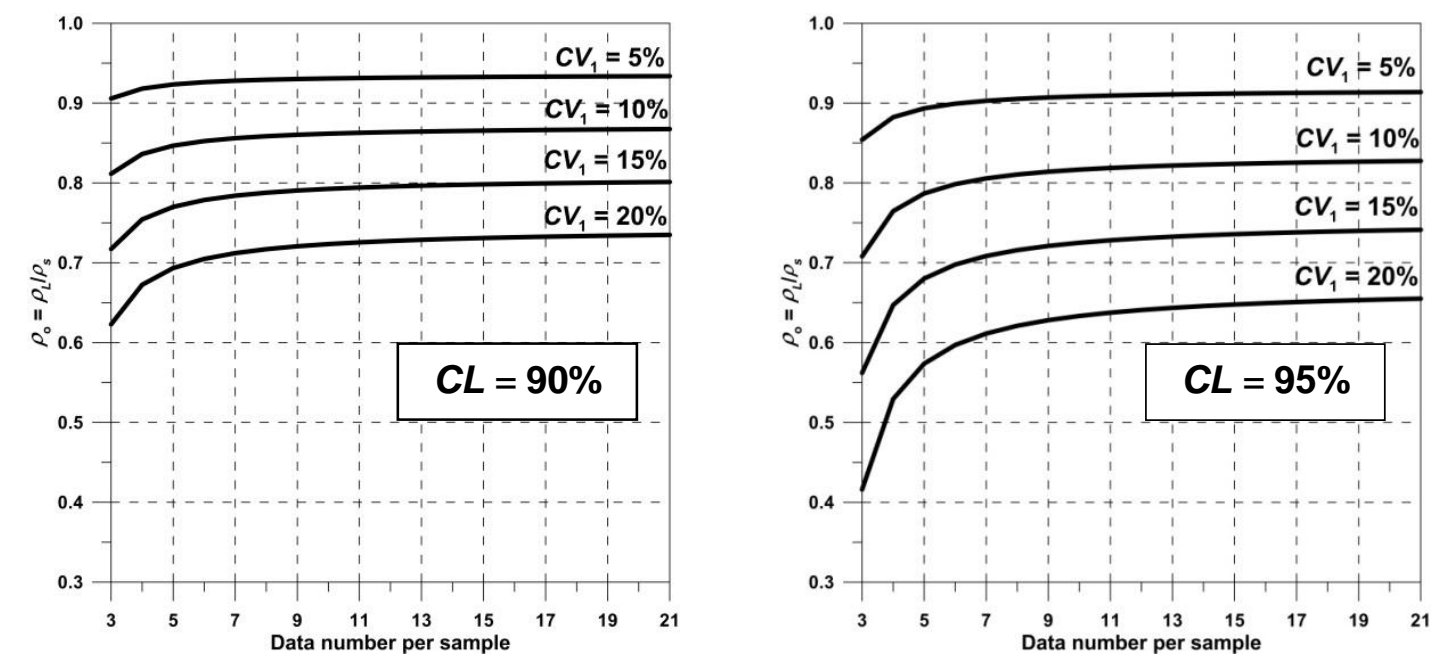

Figure 11. Relative lower tolerance limits for the fibers content of the FRC, with levels of confidence $(C L)$ of $90 \%$ and $95 \%$, and different values of the expected coefficients of variation.
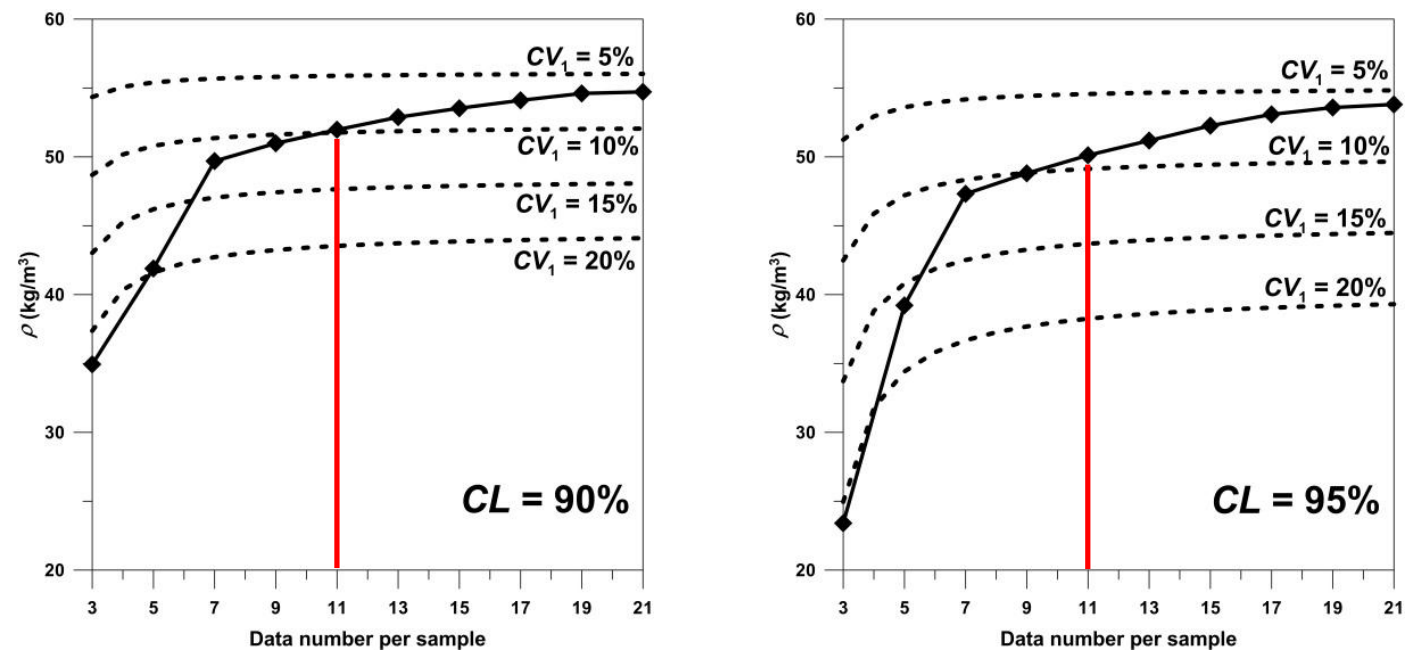

Figure 12. Minimum values of the lower limits of the confidence intervals for confidence levels of $90 \%$ and $95 \%$, and lower limits of tolerance of the fibers content as function of expected coefficient of variation 
Table 1-Concrete mix proportions used to build the tunnel lining segments.

\begin{tabular}{|l|c|}
\hline \multicolumn{1}{|c|}{ Component } & $\begin{array}{c}\text { Proportion } \\
\mathrm{kg} / \mathrm{m}^{3}\end{array}$ \\
\hline Cement CEM I 52,5R & 410 \\
\hline Sand, 0-5 mm & 580 \\
\hline Granitic sand, 0-5 mm & 333 \\
\hline Granitic gravel, 5-12 mm & 410 \\
\hline Granitic gravel, 12-20 mm & 595 \\
\hline Water & 115 \\
\hline Super plasticizer admixture & 3 \\
\hline Steel fibers Wirand FF1 & 60 \\
\hline
\end{tabular}

Table 2. Control tests results of SFRC used in the tunnel lining segments.

\begin{tabular}{|l|c|c|c|}
\hline & $\begin{array}{c}\text { Compressive } \\
\text { strength } \\
f_{c}\end{array}$ & $\begin{array}{c}\text { First crack } \\
\text { strength } \\
f_{c t}\end{array}$ & $\begin{array}{c}\text { Equivalent } \\
\text { tensile strength } \\
f_{c t, k e q 300}\end{array}$ \\
\hline Number of tests & 36 & 10 & 12 \\
\hline Mean strength $(\mathrm{MPa})$ & 54.13 & 6.67 & 5.62 \\
\hline Minimum strength $(\mathrm{MPa})$ & 47.57 & 5.51 & 4.80 \\
\hline Maximum strength $(\mathrm{MPa})$ & 60.20 & 7.30 & 7.35 \\
\hline CoV $(\%)$ & 5.37 & 9.3 & 11.9 \\
\hline
\end{tabular}

Table 3. Characterization of the properties of concrete by means of BCN test.

\begin{tabular}{|c|c|c|c|c|c|}
\hline & $\begin{array}{c}P_{\max } \\
\mathrm{kN}\end{array}$ & $\begin{array}{c}P_{2} \\
\mathrm{kN}\end{array}$ & $\begin{array}{c}T_{2} \\
\mathrm{Nm}\end{array}$ & $\begin{array}{c}P_{6} \\
\mathrm{kN}\end{array}$ & $\begin{array}{c}T_{6} \\
\mathrm{Nm}\end{array}$ \\
\hline Mean value & 117.8 & 59.0 & 182.8 & 22.9 & 322.2 \\
\hline CoV (\%) & 9.3 & 39.5 & 23.1 & 46.4 & 29.2 \\
\hline Minimum & 116.4 & 17.2 & 87.2 & 5.5 & 160.2 \\
\hline Maximum & 202.5 & 110.6 & 263.4 & 55.5 & 514.5 \\
\hline
\end{tabular}


Table 4. Fiber contents $\left(\mathrm{kg} / \mathrm{m}^{3}\right)$ determined from specimens with different diameter.

\begin{tabular}{|c|c|c|c|c|c|c|c|c|c|c|c|c|c|c|}
\hline & \multicolumn{14}{|c|}{ Fiber content $\mathrm{kg} / \mathrm{m}^{3}$} \\
\hline & \multicolumn{10}{|c|}{ Central zone } & \multicolumn{2}{|c|}{$\begin{array}{c}\text { Intermediate } \\
\text { zone }\end{array}$} & \multicolumn{2}{|c|}{$\begin{array}{l}\text { Corner } \\
\text { zone }\end{array}$} \\
\hline & \multicolumn{5}{|c|}{$d=75 \mathrm{~mm}$} & \multicolumn{3}{|c|}{$d=100 \mathrm{~mm}$} & \multicolumn{6}{|c|}{$d=150 \mathrm{~mm}$} \\
\hline & In & It & It & & Ex & In & It & Ex & Ex & In & Ex & In & Ex & In \\
\hline \multirow{4}{*}{ 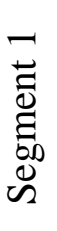 } & 70.9 & 59.9 & 63. & & 73.2 & 55.9 & 65.5 & 52.4 & \multirow{2}{*}{64.9} & \multirow{2}{*}{78.1} & \multirow{4}{*}{73.2} & \multirow{4}{*}{59.3} & 56.9 & 89.8 \\
\hline & 69.6 & 80.1 & 86. & & 61.4 & 57.1 & 61.1 & 52.9 & & & & & 62.8 & 75.6 \\
\hline & 64.8 & 71.8 & 72. & & 65.1 & 60.9 & 68.7 & 67.7 & \multirow{2}{*}{67.8} & \multirow{2}{*}{71.5} & & & 61.2 & 71.3 \\
\hline & 65.6 & 69.9 & 73. & & 75.4 & 60.8 & 62.6 & 59.1 & & & & & 65.2 & 70.6 \\
\hline \multirow{4}{*}{  } & 66.7 & 48.6 & 59. & & 67.4 & 66.7 & 64.0 & 75.2 & \multirow{2}{*}{80.1} & \multirow{2}{*}{65.2} & \multirow{4}{*}{58.3} & \multirow{4}{*}{63.1} & 52.6 & 76.3 \\
\hline & 46.5 & 84.7 & 77. & & 47.6 & 57.4 & 73.1 & 55.6 & & & & & 63.3 & 73.5 \\
\hline & 49.0 & 60.4 & 49. & & 53.8 & 74.6 & 58.5 & 50.6 & \multirow{2}{*}{69.1} & \multirow{2}{*}{58.1} & & & 58.5 & 75.8 \\
\hline & 57.5 & 70.7 & 63. & & 54.6 & 61.9 & 70.5 & 62.3 & & & & & 58.6 & 63.7 \\
\hline \multirow{4}{*}{ 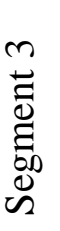 } & 52.4 & 54.1 & 41. & & 51.5 & 50.3 & 51.3 & 37.6 & \multirow{2}{*}{45.6} & \multirow{2}{*}{46.3} & \multirow{4}{*}{52.9} & \multirow{4}{*}{59.4} & 96.1 & 66.4 \\
\hline & 51.7 & 57.0 & 31. & & - & 46.0 & 50.4 & 28.5 & & & & & 60.3 & 60.6 \\
\hline & 45.5 & 38.0 & 60. & & 54.5 & 40.7 & 39.7 & 37.4 & \multirow{2}{*}{40.6} & \multirow{2}{*}{46.8} & & & 66.9 & 60.6 \\
\hline & 67.0 & 43.0 & 45. & & 52.4 & 46.2 & 42.2 & 42.7 & & & & & 66.4 & 64.0 \\
\hline
\end{tabular}

In: Intrados It: Intermediate Ex: Extrados 
Table 5. Fibers contents at each sampling point with specimens of $d=150 \mathrm{~mm}$.

\begin{tabular}{|c|c|c|c|c|}
\hline \multirow{2}{*}{ Zone } & \multirow{2}{*}{ Segment } & \multirow{2}{*}{ Sample } & \multicolumn{2}{|c|}{ Fiber contents $\mathrm{kg} / \mathrm{m}^{3}$} \\
\hline & & & Individual, $\rho_{\mathrm{i}}$ & Average \\
\hline \multirow{6}{*}{ CENTRAL } & \multirow{2}{*}{1} & 1 & 71.5 & \multirow{2}{*}{$\begin{array}{l}70.6 \\
(8.1)\end{array}$} \\
\hline & & 2 & 69.7 & \\
\hline & \multirow{2}{*}{2} & 3 & 72.7 & \multirow{2}{*}{$\begin{array}{c}68.1 \\
(13.5)\end{array}$} \\
\hline & & 4 & 63.6 & \\
\hline & \multirow{2}{*}{3} & 5 & 46.0 & \multirow{2}{*}{$\begin{array}{l}44.9 \\
(6.4)\end{array}$} \\
\hline & & 6 & 43.7 & \\
\hline \multirow{12}{*}{ CORNER } & \multirow{4}{*}{1} & 7 & 73.4 & \multirow{4}{*}{$\begin{array}{c}69.2 \\
(14.9)\end{array}$} \\
\hline & & 8 & 69.2 & \\
\hline & & 9 & 66.3 & \\
\hline & & 10 & 67.9 & \\
\hline & \multirow{4}{*}{2} & 11 & 64.5 & \multirow{4}{*}{$\begin{array}{c}65.3 \\
(13.7)\end{array}$} \\
\hline & & 12 & 68.4 & \\
\hline & & 13 & 67.2 & \\
\hline & & 14 & 61.2 & \\
\hline & \multirow{4}{*}{3} & 15 & 81.3 & \multirow{4}{*}{$\begin{array}{c}67.7 \\
(17.5)\end{array}$} \\
\hline & & 16 & 60.5 & \\
\hline & & 17 & 63.8 & \\
\hline & & 18 & 65.2 & \\
\hline \multirow{3}{*}{ INTERMEDIATE } & 1 & 19 & 66.3 & 66.3 \\
\hline & 2 & 20 & 60.7 & 60.7 \\
\hline & 3 & 21 & 56.2 & 56.2 \\
\hline
\end{tabular}

( ): Coefficient of variation, $\%$

Table 6. Statistical parameters of the samples used to evaluate the fiber content across the segments thickness.

\begin{tabular}{|l|c|c|}
\hline \multicolumn{1}{|c|}{ Parameter } & $\begin{array}{c}\text { Extrados } \\
\text { side }\end{array}$ & $\begin{array}{c}\text { Intrados } \\
\text { side }\end{array}$ \\
\hline Average, $\mathrm{kg} / \mathrm{m}^{3}$ & 62.9 & 66.5 \\
\hline Standard deviation, $\mathrm{kg} / \mathrm{m}^{3}$ & 11.6 & 10.3 \\
\hline $\mathrm{CoV}, \%$ & 18.5 & 15.5 \\
\hline Minimum, $\mathrm{kg} / \mathrm{m}^{3}$ & 40.6 & 46.3 \\
\hline Maximum, $\mathrm{kg} / \mathrm{m}^{3}$ & 96.1 & 89.8 \\
\hline
\end{tabular}


Table 7. Statistical parameters of each analyzed samples.

\begin{tabular}{|l|c|c|c|}
\hline \multirow{2}{*}{ Parameter } & \multicolumn{3}{|c|}{ Diameter $(\mathrm{mm})$} \\
\cline { 2 - 4 } & 75 & 100 & 150 \\
\hline Data number & 47 & 36 & 12 \\
\hline Mean, $\mathrm{kg} / \mathrm{m}^{3}$ & 60.2 & 55.8 & 61.2 \\
\hline Standard deviation, $\mathrm{kg} / \mathrm{m}^{3}$ & 12.4 & 11.5 & 13.5 \\
\hline CoV, \% & 20.6 & 20.6 & 22.0 \\
\hline Minimum, kg/m & 31.5 & 28.5 & 40.6 \\
\hline Maximum, kg/m & 86.9 & 75.2 & 80.1 \\
\hline
\end{tabular}


